\title{
Age at calving in heifers and level of milk production during gestation in cows are associated with the birth size of Holstein calves
}

\author{
M. M. Kamal, ${ }^{*}$ M. Van Eetvelde, ${ }^{*}$ E. Depreester, ${ }^{*}$ M. Hostens, ${ }^{*}$ L. Vandaele, $†$ and G. Opsomer ${ }^{* 1}$ \\ *Department of Reproduction, Obstetrics and Herd Health, Faculty of Veterinary Medicine, Ghent University, Salisburylaan 133,9820 Merelbeke, \\ Belgium \\ †Department of Animal Sciences, Institute for Agricultural and Fishery Research (ILVO), Scheldeweg 68, 9090 Melle, Belgium
}

\begin{abstract}
The objective of the present study was to evaluate environmental and dam factors associated with birth size of Holstein calves. Data of 1,594 births from dairy herds in Belgium and Germany were analyzed in a retrospective cross-sectional study. Immediately after birth, the birth weight of the calves was measured. On the next day, the heart girth (HG), withers height, and diagonal length of the dams and calves were measured. Parity, body condition score, gestation length (GL), and age at calving were recorded for all dams. For the cows, days open, lactation length, length of the dry period, and calving interval were also calculated. The magnitude and shape of the lactation that took place during gestation was quantified using the MilkBot model based on monthly milk weights. Using the same procedure, cumulative milk production from conception to drying off (MGEST) was calculated. After descriptive analyses, mixed models were used to identify factors that are significantly associated with the birth weight (most consistent measure of size at birth) of the calves born to both heifers and cows. Of the variables offered to the offspring birth weight model in heifers $(\mathrm{n}=540)$, calf sex, season of calving, GL, HG, withers height, diagonal length, and age at calving were significant. The mean birth weight of the calves born to heifers was estimated to be $41.3 \pm 1.01 \mathrm{~kg}$. In comparison to calves born to old ( 25.5 to $37.3 \mathrm{mo}$; $=99$ ) heifers, the birth weight was estimated to be $2.75,3.29$, and $2.35 \mathrm{~kg}$ heavier when the calves were born to very young $(20.3$ to $<22 \mathrm{mo} ; \mathrm{n}=98)$, young $(22$ to $<23.5 \mathrm{mo} ; \mathrm{n}=145)$, and standard aged $(23.5$ to $<25.5 \mathrm{mo} ; \mathrm{n}=198)$ heifers, respectively. Of the variables offered to the offspring birth weight model in cows $(\mathrm{n}=1,054)$, calf sex, season of calving, GL, parity, dry period, and MGEST were significant. The mean birth weight of the calves born to cows was estimated to be $44.1 \pm 0.99 \mathrm{~kg}$. For cows having an identical HG, the birth weight of the calves was
\end{abstract}

Received January 3, 2014.

Accepted June 6, 2014.

${ }^{1}$ Corresponding author: Geert.Opsomer@Ugent.be estimated to be 0.97 and $1.11 \mathrm{~kg}$ higher in cows with low $(1,400$ to $<5,400 \mathrm{~kg})$ and high $(6,500$ to $<7,200)$ MGEST, respectively, compared with cows with very high $(7,200$ to $11,600 \mathrm{~kg})$ MGEST. The decisive effects of age at calving in heifers and of high milk production levels during gestation in cows on the birth weight of their calves may provide a basis for developing managerial interventions to improve long-term health and productivity of the offspring.

Key words: birth size, risk factor, heifer age, milk production

\section{INTRODUCTION}

Size at birth is important for calving ease of the dams and neonatal survival of the calves. Large calves are associated with calving difficulties (Johanson and Berger, 2003), whereas small calves are more susceptible to neonatal mortality (McCorquodale et al., 2013). Epidemiological evidence suggests that small size at birth both in humans and animals is associated with increased predisposition to metabolic diseases during adult life (Vuguin, 2007; Symonds et al., 2010). It should be noted that birth size is a complex trait influenced by the interaction between genetic and nongenetic intrauterine factors (Koçak et al., 2007). However, the intrauterine environment has been stated to be a more important regulator of birth size than the parental genome (Swali and Wathes, 2006; Sharma et al., 2012). In the current dairy industry, most heifers are bred while still growing and likely most subsequent gestations are carried during lactation. The heifers' age and cows' level of milk production during gestation have both been suggested to be important contributors to the nutritional environment for the developing embryo and fetus (Berry et al., 2008; Brickell et al., 2009; Funston and Summers, 2013), as available nutrients need to be partitioned between the growth (in heifers) and milk production (in cows) of the dam and the intrauterine growth of the offspring. We hypothesize that young age in heifers and high milk production during gestation in cows affect the intrauterine fetal development and subsequent birth size of the calf. 
The use and interpretation of birth size in relation to fetal programming assumes that birth size indeed reflects specific fetal responses to particular variations in the nutritional status of the dam. Because epigenetic adaptations in the embryo may influence future health and fertility (Wu et al., 2006; Van Soom et al., 2013), the intrauterine environment is currently being assessed with regard to health and welfare of the offspring (Rutherford et al., 2012). The association of young age in heifers and high milk production during gestation in cows with reduced longevity and productivity of their offspring (Banos et al., 2007; Berry et al., 2008; González-Recio et al., 2012) furthermore emphasizes their potential effect on birth size of the calves. Moreover, recent publications indicate that the prevalence of perinatal mortality has increased in some dairy industries, whereas an increased proportion of this loss is not associated with the longestablished risk factors for perinatal mortality (Mee et al., 2008). Hence, some evidence exists to suggest that an increasing proportion of perinatal mortality occurs at unassisted calvings (idiopathic stillbirth or weak calf syndrome) where placental dysfunction and low birth weight may be causative factors (Berglund et al., 2003; Kornmatitsuk et al., 2004). Although the underlying causes of this rather new phenomenon are not yet fully elucidated, managerial factors typically associated with modern dairy husbandry, such as young age at first calving and a high level of milk production during gestation, are often referred to as potential candidates.

Numerous studies report on the effect of environment and nutrition (Zhang et al., 2002; Koçak et al., 2007; Symonds et al., 2010) and multiple dam morphometrics (Kertz et al., 1997; Lundborg et al., 2003; Swali and Wathes, 2006) on the birth size of their calves, but information on factors inherent to the dam, such as age at calving in heifers and milk production during gestation in cows has, to the best of our knowledge, yet to be adequately documented. In studies examining the effect of the level of milk production on size and well-being of the neonatal calf, researchers used the amount of milk produced during the whole lactation or during the $305 \mathrm{~d}$ of lactation (Swali and Wathes, 2006; Berry et al., 2008) and not the amount produced during gestation or during specific moments in gestation when the overall growth of the fetal calf is of major importance. Furthermore, despite the multifactorial nature of fetal growth in Holsteins, the current literature is lacking in research where a multifactorial approach has been used to identify the key risk factors associated with birth size. The objective of the present study was to evaluate environmental and dam factors, including age at calving in heifers and level of milk production during gestation in cows that might be associated with birth size in Holstein calves.

\section{MATERIALS AND METHODS}

\section{Farms, Animals, and Management}

Data were collected from 4 small dairy herds (on average, 70 lactating cows) in Flanders (Belgium) and 1 large herd (>2,000 lactating cows) in Rostock (Germany). Herds were selected based on their long history of successful collaboration with the Ghent University Ambulatory Clinic (Merelbeke, Belgium). All herds participated in an official milk-recording system and AI program and in a veterinary herd health program to closely monitor both health and productivity. In all herds, only Holstein cows were milked and average 305d milk production was $>9,400 \mathrm{~kg}$. The heifers and cows were housed in freestall barns. They were fed according to their requirements for maintenance and growth (heifers) and production (cows), based on the results of the monthly production tests. The rations included high-quality roughages (maize silage, grass silage, sugar beet pulp, and fodder beets) supplemented with concentrates. The cows were generally milked twice per day, whereas in Germany some high-producing cows were milked 3 times. Heat detection was performed by the herdsmen and their employees at least 3 times daily at regular time intervals. In some herds, aids were used to optimize heat detection. Observed heats, as well as all other observations concerning health and fertility were carefully noted on a herd health chart or were put in a herd health computer software program. Heifers were generally inseminated at an age of 15 mo, whereas the cows were generally inseminated at the first estrus occurring after $50 \mathrm{~d}$ postpartum. Heifers and cows approaching parturition were separated in a maternity pen and were closely monitored by the farm employees. After calving, the calves were immediately removed from the maternity pen into an individual calf pen. Calves were fed $4 \mathrm{~L}$ of colostrum within the first $10 \mathrm{~h}$ after birth by esophageal tube.

\section{Measurements and Data Collection}

A retrospective cross-sectional study design was used. The outline of the measurements and data collection is shown in Figure 1. Heifers and cows were enrolled upon calving between August 2011 and April 2013. During the study period, some of the cows calved a second time and were, therefore, enrolled twice. Calves born following inseminations with semen from non-Holstein bulls $(\mathrm{n}=84)$, born dead or failed to survive during the first $24 \mathrm{~h}(\mathrm{n}=22)$, or born following an abnor- 
mally short $(<265 \mathrm{~d} ; \mathrm{n}=5)$ or long $(>295 \mathrm{~d} ; \mathrm{n}=2)$ gestation length as well as twin calves $(\mathrm{n}=66)$ were all excluded from further analyses. Calving ease was scored on a categorical scale: $0=$ nonassisted, $1=$ easy farmer assistance, $2=$ difficult farmer assistance, and $3=$ veterinary assistance, including caesareans. Body condition score of the dams was determined on a 1 to 5 scale $(1=$ emaciated, $5=$ obese $)$ with 0.25 increments (Edmonson et al., 1989). The birth date of the dam and the date of calving were recorded. The sex of the calves and the identification of their sires were also carefully recorded. Immediately after birth, the birth weight of the calves was measured in kilograms. On the next day, the heart girth (HG), withers height (WH), and diagonal length (DL) of both dams and calves were measured in centimeters. The HG was measured with a plastic-coated fiber tape as the minimal circumference around the body immediately behind the elbows. The WH and DL were measured with specially designed metal calipers on the left side while animals were in a standing position. The $\mathrm{WH}$ was defined as the distance from the floor to the top of the withers directly above the center of the shoulder, whereas the DL was defined as the distance from the leading edge of the tuberculum majus humeri to the medial border of the tuber ischiadicum. The previous calving dates, dates of conception, monthly milk weights of the lactation that started at the calving preceding the one that was included in the study, and dry-off dates were extracted from the herd databases. Because the sire breeding value in terms of offspring birth weight was not available for all bulls, the breeding value for calving ease was collected and used to estimate the sire effect.

\section{Calculations and Estimations}

The body condition index (BCI) of the calves was calculated as birth weight/(WH $\times \mathrm{DL})$. In humans, a similar measure (body mass index: weight $/$ height $^{2}$ ) incorporates standing height (i.e., the length of the spine and long bones), whereas in quadrupeds the length of the spine is not included in height. There were 540 heifer calving records in which the average age was $24.0 \pm$ 2.18 mo. Based on the distribution, age at calving was divided into 4 classes: 20.3 to $<22$ mo (very young), 22 to $<23.5 \mathrm{mo}$ (young), 23.5 to $<25.5 \mathrm{mo}$ (standard), and 25.5 to 37.3 mo (old). The gestation length $(\mathbf{G L})$ was derived both in heifers and cows from the last recorded insemination and calving date and restricted to 265 to $295 \mathrm{~d}$, as mentioned above. Days open, lactation length, dry period (DP), and calving interval in the cows were calculated. The season of calving was grouped into 2 groups: summer and fall (June 21 to December 20) and winter and spring (December 21 to June 20). Monthly milk weights were fitted to the MilkBot model (Ehrlich, 2011), which can be functionally expressed as

$$
Y(t)=a\left(1-\frac{e^{\frac{c-t}{b}}}{2}\right) e^{-d t} .
$$

This approach was used to summarize the magnitude and shape of each lactation curve, where $Y(t)$ is total daily milk production on day $t$ of the lactation, and parameters $a, b, c$, and $d$ control the shape of the curve. Specifically, lactation scale is measured by the $a$ parameter in the MilkBot function. It is a simple linear scale with equal influence at all stages of lactation. The parameter $b$, called the ramp parameter, measures the steepness of the postparturient increase in production, so it is most influenced by changes in early lactation. Higher ramp values correspond to a slower increase in production. The offset parameter, $c$, is the theoretical offset between parturition and the physiological start of lactation. Normal variability in the offset parameter is expected to be small and practically undetectable without daily milk weights in the first days of lactation; thus, the offset value was fixed to 0 in the present study. Finally, the decay parameter, $d$, relates to senescence and loss of productive capacity and is influenced by cumulative changes in productive capacity occurring

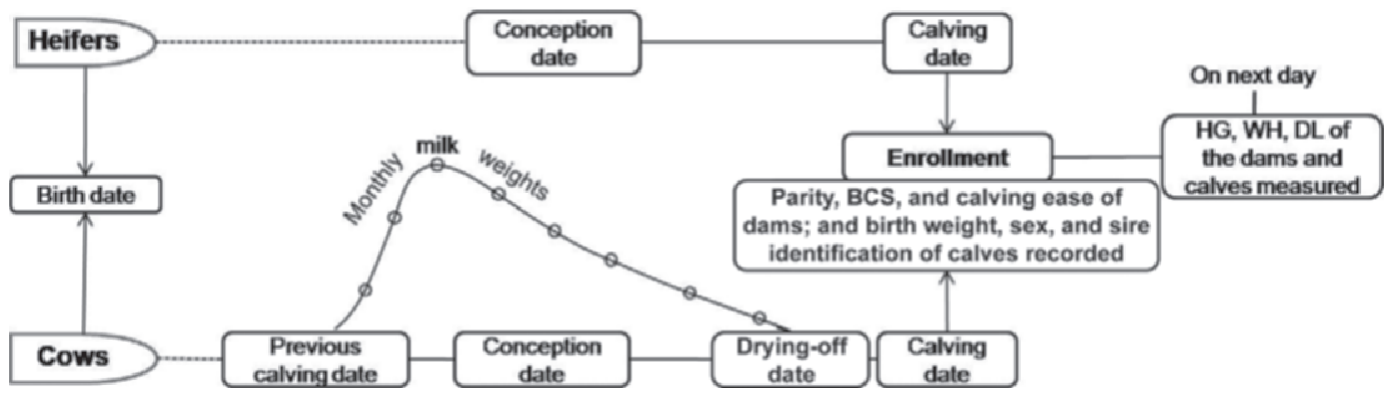

Figure 1. Outline of the measurements and data collection. HG = heart girth; $\mathrm{WH}=$ withers height; DL = diagonal length. 
throughout the lactation. As a first-order rate constant, decay can be expressed as half-life, called persistence, corresponding approximately to the time in days for production to decrease by half in late lactation (Ehrlich, 2011). This methodology allows scale, ramp, and persistence of individual lactations to be treated as independent variables in statistical models, along with the derived variables cumulative 305-d milk production (M305), cumulative milk production during gestation from conception to drying off (MGEST), milk production at lactation peak (MPEAK), cumulative milk production from $15 \mathrm{~d}$ before to $15 \mathrm{~d}$ after conception (MPCONC), time to peak milk, and time to half of the peak milk, which were all easily calculated directly from MilkBot parameter values (Ehrlich, 2011). The MGEST was further divided into 4 classes: 1,400 to $<5,400 \mathrm{~kg}$ (low), 5,400 to $<6,500 \mathrm{~kg}$ (intermediate), 6,500 to $<7,200 \mathrm{~kg}$ (high), and 7,200 to $11,600 \mathrm{~kg}$ (very high).

\section{Statistical Analyses}

All statistical analyses were performed using the SAS Enterprise Guide (version 5.0; SAS Institute Inc., Cary, $\mathrm{NC}$ ). In the descriptions given, including Table 1, original data are displayed as means \pm standard deviation, whereas model-based estimates are listed as \pm standard error. Pearson correlation coefficients (r) were esti- mated to describe relationships between variables using PROC CORR. After descriptive analysis, the data were analyzed using a linear mixed model in PROC MIXED. Separate models for heifers and cows were built to identify the significant factors of birth weight of the calves. The model equation was $y=\mathbf{X} \boldsymbol{\beta}+\mathbf{Z} \boldsymbol{\gamma}+$ $\boldsymbol{\varepsilon}$, where $y$ represents univariate data, $\boldsymbol{\beta}$ is an unknown vector of fixed effects with known model matrix $\mathbf{X}, \gamma$ is an unknown vector of random effects with known model matrix $\mathbf{Z}$, and $\varepsilon$ is an unknown random error vector. The variance explained $\left(\mathrm{R}^{2}\right)$ by the models was expressed as the ratio between the residual variance of the model of interest and the residual variance of the null model.

The heifer model included fixed effects of calf sex, season of calving, GL, HG, WH, DL, BCS, and age at calving. The herds were specified as random effect term. For cows, the model included fixed effects of calf sex, season of calving, GL, HG, WH, DL, BCS, parity/age at calving, days open, lactation length, calving interval, ramp, persistence, time to peak milk, time to half of the peak milk, MGEST, and DP. In the model for cows, herds were included as random effect and second-time measurements on the same cows were accounted for by the repeated statement. All fixed effects and their 2-way interactions were included in the initial model, but removed if found nonsignificant $(P>0.05)$, after which the model was refitted. The scale, M305,

Table 1. The characteristics of the dams and their calves (mean \pm SD)

\begin{tabular}{|c|c|c|}
\hline Outcome $^{1}$ & Heifers $(\mathrm{n}=540)$ & Cows $(\mathrm{n}=1,054)$ \\
\hline \multicolumn{3}{|l|}{ Dams } \\
\hline Heart girth $(\mathrm{cm})$ & $201.1 \pm 6.82^{\mathrm{a}}$ & $214.0 \pm 9.52^{\mathrm{b}}$ \\
\hline Withers height $(\mathrm{cm})$ & $140.0 \pm 4.39^{\mathrm{a}}$ & $144.5 \pm 5.45^{\mathrm{b}}$ \\
\hline Diagonal length $(\mathrm{cm})$ & $159.4 \pm 6.33^{\mathrm{a}}$ & $170.3 \pm 7.15^{\mathrm{b}}$ \\
\hline Age at calving (mo) & $24.0 \pm 2.18^{\mathrm{a}}$ & $51.6 \pm 16.87^{\mathrm{b}}$ \\
\hline Gestation length (d) & $278.1 \pm 4.36^{\mathrm{a}}$ & $280.0 \pm 4.66^{\mathrm{b}}$ \\
\hline Scale (kg) & - & $45.7 \pm 10.43$ \\
\hline $\operatorname{Ramp}(\mathrm{d})$ & - & $24.4 \pm 7.85$ \\
\hline Persistence (d) & - & $375.3 \pm 241.91$ \\
\hline M305 (kg) & - & $9,409.1 \pm 1,639.15$ \\
\hline MGEST (kg) & - & $6,193.1 \pm 1,352.79$ \\
\hline MPEAK (kg) & - & $38.6 \pm 8.32$ \\
\hline MPCONC (kg) & - & $1,045.1 \pm 222.65$ \\
\hline Days open (d) & - & $108.7 \pm 55.53$ \\
\hline Lactation length (d) & - & $332.4 \pm 51.25$ \\
\hline Dry period (d) & - & $56.2 \pm 21.12$ \\
\hline \multicolumn{3}{|l|}{ Calves } \\
\hline Birth weight (kg) & $40.6 \pm 4.90^{\mathrm{a}}$ & $45.2 \pm 5.58^{\mathrm{b}}$ \\
\hline Heart girth $(\mathrm{cm})$ & $79.2 \pm 3.63^{\mathrm{a}}$ & $81.9 \pm 3.60^{\mathrm{b}}$ \\
\hline Withers height $(\mathrm{cm})$ & $74.6 \pm 3.70^{\mathrm{a}}$ & $76.2 \pm 3.66^{\mathrm{b}}$ \\
\hline Diagonal length $(\mathrm{cm})$ & $68.6 \pm 3.99^{\mathrm{a}}$ & $70.9 \pm 3.92^{\mathrm{b}}$ \\
\hline Body condition index & $79.3 \pm 7.60^{\mathrm{a}}$ & $83.5 \pm 8.63^{\mathrm{b}}$ \\
\hline
\end{tabular}

${ }_{\mathrm{a}, \mathrm{b}}$ Values within a row with different superscript letters are significantly different (all at $P<0.001$ ).

${ }^{1} \mathrm{M} 305$ = cumulative 305-d milk production; MGEST = cumulative milk production during gestation from conception to drying off; MPEAK = milk production at lactation peak; MPCONC $=$ cumulative milk production from $15 \mathrm{~d}$ before to $15 \mathrm{~d}$ after conception; body condition index $=$ birth weight/(withers height $\times$ diagonal length). 
MPEAK, and MPCONC were not included in the initial model because of their high correlation $(>60 \%)$ with MGEST. Separate similar models were built with these variables by replacing MGEST (data not shown). Both in heifers and cows, the inclusion of sire breeding values for calving ease did not significantly improve the model and, therefore, were excluded. Data of the final models are reported as model least squares means, unless indicated otherwise.

\section{RESULTS}

\section{Descriptions}

The characteristics of the dams and calves are presented in Table 1. The overall average birth weight of the calves was $43.6 \pm 5.78 \mathrm{~kg}$, the calves born to heifers $(\mathrm{n}=540)$ being $4.6 \mathrm{~kg}$ lighter compared with the ones delivered by the cows $(\mathrm{n}=1,054 ; 40.6 \pm 4.90$ vs. $45.2 \pm 5.58 \mathrm{~kg}$, respectively). The calves born to the heifers were significantly smaller in $\mathrm{HG}, \mathrm{WH}, \mathrm{DL}$, and BCI compared with the ones born to the cows $(P<$ 0.001). The birth weight had the greatest correlation with HG $(\mathrm{r}=0.75 ; P<0.001)$ and BCI $(\mathrm{r}=0.71 ; P<$ 0.001 ) of the calves. The birth weight of both male and female calves increased with parity of the dams, and experienced a decrease from the fourth parity (Figure 2 ). The level of calving assistance increased with increased birth weight of both male and female calves $(P$ $<0.001$ ). The sire breeding value for calving ease was negatively correlated $(\mathrm{r}=-0.22 ; P<0.001)$ with birth weight of the calves. The heifers had a 1.9-d shorter $(278.1 \pm 4.36$ vs. $280.0 \pm 4.66)$ GL than the cows $(P<$ 0.001). The male calves were carried, on average, $1.3 \mathrm{~d}$ longer $(280.0 \pm 4.69$ vs. $278.7 \pm 4.51)$ than the female calves $(P<0.001)$.

\section{Factors Influencing Offspring Birth Weight in Heifers}

Of the variables offered to the offspring birth weight model in heifers, calf sex, season of calving, GL, HG, WH, DL, and age at calving were significant (Table 2). The proposed model explains $29.5 \%$ of the variation in birth weight of the calves born to heifers. The mean birth weight of the calves born to heifers was estimated to be $41.3 \pm 1.01 \mathrm{~kg}$. Male calves were estimated to have a $2.57 \mathrm{~kg}$ higher birth weight than female calves, and the calves born in the summer and fall were estimated to be $2.23 \mathrm{~kg}$ lighter than the calves born in the winter and spring $(P<0.001)$. Calves born following a short (265-275 d) and medium (276-285 d) GL were estimated to be 5.01 and $2.18 \mathrm{~kg}$ lighter, respectively, compared with the calves born following a long (286-295 d) GL $(P<0.001)$. The birth weight of the calves was estimated to increase by $0.52,0.54$, and 0.73 $\mathrm{kg}$ with each centimeter increase in $\mathrm{HG}, \mathrm{WH}$, and $\mathrm{DL}$ of the heifers at calving, respectively $(P<0.01)$. The birth weight was estimated to be significantly lower in the heifers that calved at an old age (25.5 to 37.3 mo; $P$ $<0.001)$. The calves born to very young $(20.3$ to $<22$ mo) and standard aged ( 23.5 to $<25.5 \mathrm{mo})$ heifers were estimated to be lighter compared with calves born to young $(22$ to $<23.5 \mathrm{mo}$ ) heifers (Table 2 ).

\section{Factors Influencing Offspring Birth Weight in Cows}

Of the variables offered to the offspring birth weight model in cows, calf sex, season of calving, GL, parity, DP, and MGEST were significant (Table 3). The present model explains $26.2 \%$ of the variation in birth weight of the calves delivered by the cows. The mean birth weight of the calves born to cows was estimated to be $44.1 \pm 0.99 \mathrm{~kg}$. Male calves were estimated to be $3.51 \mathrm{~kg}$ heavier than the female calves, and the calves born in the summer and fall were estimated to be 1.12 $\mathrm{kg}$ lighter than the calves born in the winter and spring $(P<0.001)$. Calves born after a short $(265-275 \mathrm{~d})$ and medium (276-285 d) GL were estimated to be 4.96 and $2.52 \mathrm{~kg}$ lighter, respectively, compared with those born after a long $(286-295)$ GL $(P<0.001)$. Cows in their second and third parities gave birth to calves that were estimated to be $1.02 \mathrm{~kg}$ heavier compared with calves born to older cows $(P=0.005)$. For cows having an identical HG, the birth weight of the calves was estimated to be 0.97 and $1.11 \mathrm{~kg}$ higher in cows with low $(1,400$ to $<5,400 \mathrm{~kg})$ and high $(6,500$ to $<7,200)$ MGEST, respectively, compared with cows with very high $(7,200$ to $11,600 \mathrm{~kg})$ MGEST $(P<0.05)$. The

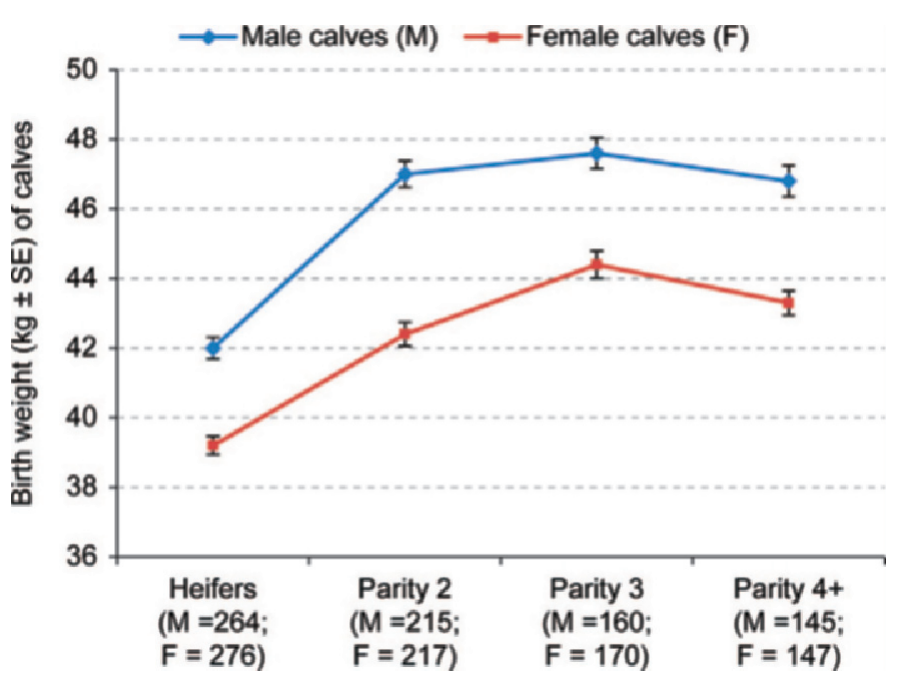

Figure 2. Birth weight of the calves in relation to their sex and parity of their dam. Color version available in the online PDF. 
Table 2. Significant predictors of birth weight $(\mathrm{kg})$ of calves born to heifers

\begin{tabular}{llccc}
\hline Predictor & Comparison & No. & Estimate $(\mathrm{kg})$ & $P$-value \\
\hline Intercept & & 540 & 41.3 & $<0.001$ \\
Calf sex & Male & 264 & 2.57 & $<0.001$ \\
& Female & 276 & Referent & \\
Season of calving & Summer and fall & 325 & -2.23 & $<0.001$ \\
& Winter and spring & 215 & Referent & \\
Gestation length $(\mathrm{d})$ & Short $(265$ to 275$)$ & 136 & -5.01 & $<0.001$ \\
& Medium $(276$ to 285$)$ & 379 & -2.18 & 0.011 \\
Heart girth $(\mathrm{cm})$ & Long $(286$ to 295$)$ & 25 & Referent & \\
Wither height $(\mathrm{cm})$ & Linear & 540 & 0.52 & 0.016 \\
Diagonal length $(\mathrm{cm})$ & Linear & 540 & 0.54 & 0.007 \\
Age at calving $(\mathrm{mo})$ & Linear & 540 & 0.73 & $<0.001$ \\
& Very young $(20.3$ to $<22)$ & 98 & 2.75 & $<0.001$ \\
& Young $(22$ to $<23.5)$ & 145 & 3.29 & $<0.001$ \\
& Standard $(23.5$ to $<25.5)$ & 198 & 2.35 & $<0.001$ \\
\hline
\end{tabular}

birth weight of the calves was estimated to be 1.14 and $1.60 \mathrm{~kg}$ higher in cows that had passed a long ( 55 to $275 \mathrm{~d}$ ) and medium ( 45 to $54 \mathrm{~d}$ ) DP respectively, compared with cows having passed a short $(<45 \mathrm{~d}) \mathrm{DP}$ $(P=0.002$; Table 3$)$.

\section{DISCUSSION}

The present study provides new insight about some factors that are significantly associated with birth size of Holstein calves. Several studies have been published on the effect of specific environmental factors in relation to birth size (Zhang et al., 2002; Swali and Wathes, 2006; Koçak et al., 2007). However, what is lacking is an evaluation of the combined effect of all of these variables, including the age at calving in heifers and the amount of milk produced during specific moments in gestation in cows. Age at calving and milk production during gestation are identified as important determinants of calf birth size in heifers and cows, respectively. Moreover, calf sex, season of calving, GL, parity, and morphometrics (HG, WH, and DL) of the dam and DP are reaffirmed as factors being significantly associated with calf birth size. In addition, we found a weak correlation between sire breeding value for calving ease and birth weight of the calves. This result supports previous investigations (Swali and Wathes, 2006) in suggesting that the uterine environment has a greater influence on size at birth than the paternal genotype.

As in previous studies (Koçak et al., 2007; Swali et al., 2008), birth weight was retained as the most con-

Table 3. Significant predictors of birth weight $(\mathrm{kg})$ of calves born to cows

\begin{tabular}{|c|c|c|c|c|}
\hline Predictor & Comparison & No. & Estimate (kg) & $P$-value \\
\hline Intercept & & 1,054 & 44.1 & $<0.001$ \\
\hline \multirow[t]{2}{*}{ Calf sex } & Male & 520 & 3.51 & $<0.001$ \\
\hline & Female & 534 & Referent & \\
\hline \multirow[t]{2}{*}{ Season of calving } & Summer and fall & 570 & -1.12 & $<0.001$ \\
\hline & Winter and spring & 484 & Referent & \\
\hline \multirow{3}{*}{ Gestation length (d) } & Short (265 to 275 ) & 173 & -4.96 & $<0.001$ \\
\hline & Medium (276 to 285$)$ & 765 & -2.52 & $<0.001$ \\
\hline & Long (286 to 295 ) & 116 & Referent & \\
\hline \multirow[t]{2}{*}{ Parity of the cows } & 2 and 3 & 762 & 1.02 & 0.005 \\
\hline & 4 to 9 & 292 & Referent & \\
\hline Heart girth $(\mathrm{cm})$ & Linear & 1,054 & 0.19 & 0.63 \\
\hline \multirow{4}{*}{$\operatorname{MGEST}^{1}(\mathrm{~kg})$} & Low $(1,400$ to $<5,400)$ & 270 & -1.16 & 0.021 \\
\hline & Intermediate $(5,400$ to $<6,500)$ & 334 & -0.74 & 0.083 \\
\hline & High $(6,500$ to $<7,200)$ & 222 & -0.43 & 0.34 \\
\hline & Very high $(7,200$ to $<11,600)$ & 228 & Referent & \\
\hline \multirow[t]{4}{*}{ Heart girth $\times$ MGEST $(\mathrm{cm} \cdot \mathrm{kg})$} & Low $(1,400$ to $<5,400)$ & 270 & 0.97 & 0.039 \\
\hline & Intermediate $(5,400$ to $<6,500)$ & 334 & 0.10 & 0.84 \\
\hline & High $(6,500$ to $<7,200)$ & 222 & 1.11 & 0.034 \\
\hline & Very high $(7,200$ to 11,600$)$ & 228 & Referent & \\
\hline \multirow[t]{3}{*}{ Dry period (d) } & Long ( 55 to 275 ) & 336 & 1.14 & 0.021 \\
\hline & Standard ( 45 to 54$)$ & 469 & 1.60 & $<0.001$ \\
\hline & Short (3 to 44$)$ & 249 & Referent & \\
\hline
\end{tabular}

${ }^{1}$ MGEST $=$ cumulative milk production during gestation from conception to drying off. 
sistent and objective measure to describe the size of the calves at birth. The HG and BCI are highly positively correlated with birth weight and have been used as important descriptors of birth size in comparison with other measures (Lundborg et al., 2003; Swali and Wathes, 2006). This means that the calves with lower birth weight have smaller HG and BCI, and are proportionately thinner (Swali and Wathes, 2006). Logically, the factors that influence birth weight of the calves are expected to influence their HG and BCI. Therefore, the remainder of the discussion is focused on the factors related to birth weight, the most important descriptor of birth size in calves. As in other studies (Swali et al., 2008; Sharma et al., 2012; Gutiérrez et al., 2013), birth weight estimates mentioned in the present study are based on the applied statistical models and are, therefore, conditional on taking into account the included fixed and random effects, and somewhat different from the originally measured birth weight. Furthermore, in some other species, including humans, it has been shown that detrimental environmental factors experienced by the dam during gestation (e.g., starvation or illness) do have a negative effect on embryonic or fetal development, which became clear by a lower weight of the offspring at birth (Stein et al., 2004; Sharma et al., 2012; Tao et al., 2012).

\section{Calf Sex and Dam Parity}

Calf sex is significantly associated with birth weight; male calves are heavier than female calves, as previously reported (Kertz et al., 1997; Dhakal et al., 2013; Gutiérrez et al., 2013). Male calves are carried 1.3 d longer than female calves, which may partially explain their higher birth weight (Dhakal et al., 2013). Moreover, sex-specific genes affecting insulin sensitivity, such as mutations in the glucokinase gene, may be responsible for the sex difference in birth weight. The genetically more insulin-resistant female fetus is less responsive to the trophic effects of insulin and is, therefore, lighter (Wilkin and Murphy, 2006). Calves born to heifers are $4.6 \mathrm{~kg}$ lighter than the calves delivered by cows, which is in line with results of previous studies (Johanson and Berger, 2003; Dhakal et al., 2013). As a fetal calf has an average daily weight gain of $0.5 \mathrm{~kg}$ in the last week of gestation (Norman et al., 2009; Dhakal et al., 2013), the 1.9- $\mathrm{d}$ shorter GL in heifers compared with the cows in the current study accounts for approximately $1 \mathrm{~kg}$ of the birth weight difference. Another plausible reason why heifers give birth to lighter calves is that heifers usually are still growing during their first gestation and preferentially use nutrients for their own growth rather than for the growth and development of their fetus (Funston and Summers, 2013). The latter is fur- thermore visualized by a reduced development of the placenta (Symonds et al., 2010; Funston and Summers, 2013). Moreover, the differences in nutrient partitioning in heifers versus cows are probably controlled by developmental changes in the somatotropic axis of the dam (Brickell et al., 2009). Mature cows also become more resistant to the anabolic effects of growth hormone and placental lactogen (Weber et al., 2007), resulting in a degree of insulin resistance, which allows more glucose to be transferred to the fetus in gestating cows (Bell et al., 1995). Therefore, compared with heifers, mature cows give birth to heavier calves (Johanson and Berger, 2003; Dhakal et al., 2013). The pattern of increased birth weight from first to third parity, followed by a decrease in subsequent parities, is consistent with previous investigations (Kertz et al., 1997; Linden et al., 2009). Both IGF-I and insulin concentrations remarkably decrease as cows get older (Taylor et al., 2004). Reductions in these endocrine signals likely contribute to the lower birth weight of the calves delivered by older cows (Swali and Wathes, 2006).

\section{Season of Calving and GL}

The later part of gestation is known to be critical for fetal growth. Suboptimal growth during this period predisposes calves to a lower birth weight (Zhang et al., 2002; Symonds et al., 2010). Cows calving in the summer and fall completed their last part of gestation during the hotter seasons (spring and summer). The negative effect of higher temperature on fetal growth and birth weight of calves born to both heifers and cows has been reported earlier (Linden et al., 2009; Tao et al., 2012). Several factors may contribute to the lower birth weight of the calves born in the summer and fall seasons. One possible factor is reduced DMI of the dam during the last part of gestation due to heat stress (Umphrey et al., 2001), contributing to decreased nutrient availability and, consequently, a lower birth weight (Linden et al., 2009; Norman et al., 2009). Similarly, a longer photoperiod during the second part of gestation leads to increased plasma prolactin concentrations, supporting higher milk production and thereby limiting nutrient availability for intrauterine calf growth (García-Ispierto et al., 2009). Heat stress during late gestation is furthermore associated with decreased uterine blood flow and reduced placental function, giving rise to an impaired dam-to-fetal exchange of glucose and amino acids (Reynolds et al., 1985). Another plausible factor is the shorter GL of the pregnancies during the hotter seasons (Tao et al., 2012), which has been shown to be associated with the large variation in temperature and humidity at that time (Norman et al., 2009; Dhakal et al., 2013). 


\section{Morphometrics and Age at Calving in Heifers}

Young age has been shown to affect neonatal birth weight in humans where growth of teenage mothers during gestation is associated with increased risks for low-birth-weight babies (Chen et al., 2007). Gestation at a young age necessitates not only partition of energy toward the developing fetus, but also toward the dam's own growth. In the current dairy industry, gestation in heifers usually occurs while animals are physically immature and still growing (Kertz et al., 1997). However, the effect of age at calving in heifers on birth weight of their calves has, to the best of our knowledge, not been extensively documented earlier. We hypothesized that heifers that become pregnant while still growing would give birth to significantly lighter calves. We found in the present study that heifers that are larger in $\mathrm{HG}$, WH, and DL at calving deliver significantly heavier calves, which is in concordance with previous studies (Swali and Wathes, 2006; Linden et al., 2009). However, in the present study, the calf birth weight was curvilinear with the age of the heifers at calving. Calves born to very young (20.3 to $<22 \mathrm{mo}$ ) heifers had a comparatively lower birth weight compared with calves born to young (22 to $<23.5 \mathrm{mo}$ ) heifers, suggesting that the intrauterine environment may limit fetal calf growth due to competition for nutrients with dam growth (Wathes et al., 2008). Suboptimal growth associated with low IGF-I concentrations results in heifers that conceive at an older age (Wathes et al., 2008; Brickell et al., 2009). As the IGF system can modulate the delivery of substrates to the fetus, we speculate that the lower IGF-I in older heifers during gestation may be responsible for the lighter birth weight of their calves (Wathes et al., 2008; Brickell et al., 2009; Gutiérrez et al., 2013). Moreover, the GL in heifers is curvilinear, giving rise to a shorter GL in both young and old animals compared with the intermediate-aged group, which further contributes to the lower birth weight of calves born to relatively young and old first-parity dams (Simerl et al., 1991; Norman et al., 2009). The incidence of dystocia is also illustrated to be affected by age in a curvilinear manner, with young and older heifers being more affected (Simerl et al., 1991; Johanson and Berger, 2003). Higher calving difficulties in young and older heifers are, however, possibly due to immaturity of the dam and consequently relatively oversized calves in young heifers and excessive fat deposition in the pelvis of old heifers (Raboisson et al., 2013).

\section{Milk Production and Length of the DP}

Genetic selection in Holstein cattle has resulted in larger cows with a high milk production potential. We hypothesized that the fetal calf growth and thereby the birth weight of the newborn calves is compromised in cows with high milk production during gestation (MGEST). The rationale behind this hypothesis originates from studies done in a variety of other species, including humans, in which it was found that fetal growth is significantly retarded in case of a lack of nutrients during gestation (Symonds et al., 2010; Sharma et al., 2012). This lack of nutrients can be either caused by a famine (Stein et al., 2004) or adverse environmental conditions (Tao et al., 2012). We found that among the cows with identical HG, very high MGEST $(\geq 7,200 \mathrm{~L})$ negatively affects birth weight of the newborn calves. The scale, MPEAK and MPCONC were highly correlated $(>60 \%)$ with MGEST in the present study, which is consistent with previous investigations where the lactation curves were depicted by the Wilmink function (Yamazaki et al., 2011). Similar negative effects of the other production variables as calculated by the MilkBot model, on birth weight of the calves, are observed when they replace MGEST in the mixed model (data not shown). The depletion of energy reserves in lactation overlapping with gestation negatively affects the birth weight, as reported in humans (Şengül et al., 2013). However, in contrast to the present study, milk production level has been shown to be indistinguishable among cows that had given birth to low-, average-, and high-birth-weight calves (Swali and Wathes, 2006). This may be due to the fact that in the latter study, M305 was used as a proxy for milk production during fetal growth and to the relatively small $(\mathrm{n}=65)$ sample size. Typically, dairy cows conceive and are, therefore, pregnant at the time they still produce large quantities of milk. The latter implies that they partition large amounts of glucose and amino acids toward their udder while an embryo or fetus is growing in their uterus. Glucose, insulin and IGF-I concentrations in cows are negatively correlated with their level of milk production during the production phase of the lactation (Taylor et al., 2004; Ingvartsen and Friggens, 2005). This is furthermore evidenced by a depletion of body reserves during lactation, as shown by a negative correlation between BCS and the level of milk production (Yamazaki et al., 2011). These adaptations associated with high milk production, in turn, affect glucose availability and concentrations of insulin and IGF-I for the embryo and thereby affect the growth of both the early embryo and the placenta (Green et al., 2012). Although the nutrient requirements for the embryo may be relatively low, metabolic activity is high and this represents a critical period for epigenetic control and organogenesis of subsequent fetal development (Wu et al., 2006; Van Soom et al., 2013). A poor intrauterine nutritional environment associated with lower glucose, insulin, and IGF-I 
levels in the cows may even occur in later phases of lactation due to the high persistency of milk production as is typically noticed in modern high-yielding dairy cows (Ingvartsen and Friggens, 2005). These phases of lactation often coincide with the mid and late part of gestation, which are known to be most crucial in terms of fetal growth. Therefore, the effects of variation in nutritional environment at that time may even have greater effects than in early gestation (Stein et al., 2004; Wu et al., 2006). For example, significant reductions in birth weight have been shown to be caused by low plasma glucose concentrations during mid and late gestation (Zhang et al., 2002). The close relationship between fetal glucose uptake and dam glucose levels would explain a large part of the mechanism whereby the nutritional level of the dam affects fetal growth (Bell et al., 1995). Therefore, selection for greater milk production and high persistency in dairy cows may lead to reduced glucose availability for the developing embryo and fetus, with subsequent deleterious repercussions for birth weight of the calves, including their survival and lifetime performance (Banos et al., 2007; Berry et al., 2008; González-Recio et al., 2012).

In the current study, the calf birth weight was higher in cows with a medium ( 45 to $54 \mathrm{~d}$ ) and long (55 to 275 d) DP than in cows with a short DP (3 to $44 \mathrm{~d}$ ). Similar findings have been reported earlier; the average offspring birth weight was lower in cows having passed a DP of 51 to $60 \mathrm{~d}$ compared with those having gone through a longer DP (Atashi et al., 2013). On the other hand, in the latter study, calf birth weight did not differ for cows with DP of 0 to $35 \mathrm{~d}$, 36 to $50 \mathrm{~d}$, or 51 to $60 \mathrm{~d}$ (Atashi et al., 2013). Longer DP is associated with heavier calves and subsequently with a higher incidence of dystocia (Atashi et al., 2013). In our study, the cows with higher milk production tended to have a shorter subsequent DP, which is in line with previous reports (Atashi et al., 2013). In less productive cows, daily milk production often decreases to low levels before the planned drying-off date; therefore, farmers no longer keep these cows in production, which results in longer DP compared with higher-yielding cows (Atashi et al., 2013). Although no difference exists in serum glucose, insulin, and IGF-I levels in cows with short versus longer DP (Pezeshki et al., 2007), we speculate that cessation of partitioning nutrients toward milk for extended duration in the case of a longer DP provides higher amounts of energy and amino acids toward fetal growth, giving rise to higher birth weight of the calves.

\section{CONCLUSIONS}

The present study was undertaken to investigate the effect of environmental and dam factors on the birth weight of Holstein calves. Conclusively, results of the present study reaffirm calf sex, season of calving, GL, parity, morphometrics of the dam, and length of the DP to be significantly associated with calf birth size. Furthermore, age at calving in heifers and level of milk production during gestation in cows were indicated as decisive determinants of calf birth size. These novel findings may provide a basis for developing managerial interventions to improve long-term health and productivity of the offspring.

\section{ACKNOWLEDGMENTS}

We thank both the farm staffs and the veterinary students who contributed to this study. The study was funded by the Special Research Fund (BOF; dossier number: 01SF2010) of Ghent University (Merelbeke, Belgium).

\section{REFERENCES}

Atashi, H., M. J. Zamiri, and M. Dadpasand. 2013. Association between dry period length and lactation performance, lactation curve, calf birth weight, and dystocia in Holstein dairy cows in Iran. J. Dairy Sci. 96:3632-3638. http://dx.doi.org/10.3168/ jds.2012-5943.

Banos, G., S. Brotherstone, and M. P. Coffey. 2007. Prenatal maternal effects on body condition score, female fertility, and milk yield of dairy cows. J. Dairy Sci. 90:3490-3499. http://dx.doi. org/10.3168/jds.2006-809.

Bell, A. W., R. Slepetis, and R. A. Ehrhardt. 1995. Growth and accretion of energy and protein in the gravid uterus during late pregnancy in Holstein cows. J. Dairy Sci. 78:1954-1961.

Berglund, B., L. Steinbock, and M. Elvander. 2003. Causes of stillbirth and time of death in Swedish Holstein calves examined post mortem. Acta Vet. Scand. 44:111-120. http://dx.doi. org/10.1186/1751-0147-44-111.

Berry, D. P., P. Lonergan, S. T. Butler, A. R. Cromie, T. Fair, F. Mossa, and A. C. O. Evans. 2008. Negative influence of high maternal milk production before and after conception on offspring survival and milk production in dairy cattle. J. Dairy Sci. 91:329-337. http://dx.doi.org/10.3168/jds.2007-0438.

Brickell, J. S., N. Bourne, M. M. McGowan, and D. C. Wathes. 2009. Effect of growth and development during the rearing period on the subsequent fertility of nulliparous Holstein-Friesian heifers. Theriogenology 72:408-416. http://dx.doi.org/10.1016/j.theriogenology.2009.03.015.

Chen, X.-K., S. W. Wen, N. Fleming, K. Demissie, G. G. Rhoads, and M. Walker. 2007. Teenage pregnancy and adverse birth outcomes: A large population based retrospective cohort study. Int. J. Epidemiol. 36:368-373. http://dx.doi.org/10.1093/ije/dyl284.

Dhakal, K., C. Maltecca, J. P. Cassady, G. Baloche, C. M. Williams, and S. P. Washburn. 2013. Calf birth weight, gestation length, calving ease, and neonatal calf mortality in Holstein, Jersey, and crossbred cows in a pasture system. J. Dairy Sci. 96:690-698. http://dx.doi.org/10.3168/jds.2012-5817.

Edmonson, A. J., I. J. Lean, L. D. Weaver, T. Farver, and G. Webster. 1989. A body condition scoring chart for Holstein dairy cows. J. Dairy Sci. 72:68-78.

Ehrlich, J. 2011. Quantifying shape of lactation curves, and benchmark curves for common dairy breeds and parities. Bovine Pract. 45:88-95.

Funston, R. N., and A. F. Summers. 2013. Effect of prenatal programming on heifer development. Vet. Clin. North Am. Food Anim. Pract. 29:517-536. http://dx.doi.org/10.1016/j.cvfa.2013.07.001. 
García-Ispierto, I., F. López-Gatius, S. Almería, J. Yániz, P. Santolaria, B. Serrano, G. Bech-Sàbat, C. Nogareda, J. Sulon, N. M. de Sousa, and J. F. Beckers. 2009. Factors affecting plasma prolactin concentrations throughout gestation in high producing dairy cows. Domest. Anim. Endocrinol. 36:57-66. http://dx.doi. org/10.1016/j.domaniend.2008.10.004.

González-Recio, O., E. Ugarte, and A. Bach. 2012. Trans-generational effect of maternal lactation during pregnancy: A Holstein cow model. PLoS ONE 7:e51816 http://dx.doi.org/10.1371/journal. pone. 0051816 .

Green, J. C., J. P. Meyer, A. M. Williams, E. M. Newsom, D. H. Keisler, and M. C. Lucy. 2012. Pregnancy development from day 28 to 42 of gestation in postpartum Holstein cows that were either milked (lactating) or not milked (not lactating) after calving. Reproduction 143:699-711. http://dx.doi.org/10.1530/REP-110461.

Gutiérrez, V., A. C. Espasandin, A. L. Astessiano, A. Casal, C. LópezMazz, and M. Carriquiry. 2013. Calf foetal and early life nutrition on grazing conditions: Metabolic and endocrine profiles and body composition during the growing phase. J. Anim. Physiol. Anim. Nutr. (Berl.) 97:720-731. http://dx.doi.org/10.1111/j.14390396.2012.01314.x.

Ingvartsen, K. L., and N. C. Friggens. 2005. To what extent do variabilities in hormones, metabolites and energy intake explain variability in milk yield? Domest. Anim. Endocrinol. 29:294-304. http://dx.doi.org/10.1016/j.domaniend.2005.05.001.

Johanson, J. M., and P. J. Berger. 2003. Birth weight as a predictor of calving ease and perinatal mortality in Holstein cattle. J. Dairy Sci. 86:3745-3755.

Kertz, A. F., L. F. Reutzel, B. A. Barton, and R. L. Ely. 1997. Body weight, body condition score, and wither height of prepartum Holstein cows and birth weight and sex of calves by parity: A database and summary. J. Dairy Sci. 80:525-529.

Koçak, S., M. Tekerli, C. Özbeyaz, and B. Yüceer. 2007. Environmental and genetic effects on birth weight and survival rate in Holstein calves. Turk. J. Vet. Anim. Sci. 31:241-246.

Kornmatitsuk, B., E. Dahl, E. Ropstad, J. E. Beckers, H. Gustafsson, and H. Kindahl. 2004. Endocrine profiles, haematology and pregnancy outcomes of late pregnant Holstein dairy heifers sired by bulls giving a high or low incidence of stillbirth. Acta Vet. Scand. 45:47-68. http://dx.doi.org/10.1186/1751-0147-45-47.

Linden, T. C., R. C. Bicalho, and D. V. Nydam. 2009. Calf birth weight and its association with calf and cow survivability, disease incidence, reproductive performance, and milk production. J. Dairy Sci. 92:2580-2588. http://dx.doi.org/10.3168/jds.20081603.

Lundborg, G. K., P. A. Oltenacu, D. O. Maizon, E. C. Svensson, and P. G. A. Liberg. 2003. Dam-related effects on heart girth at birth, morbidity and growth rate from birth to 90 days of age in Swedish dairy calves. Prev. Vet. Med. 60:175-190. http://dx.doi. org/10.1016/S0167-5877(03)00106-5.

McCorquodale, C. E., A. Sewalem, F. Miglior, D. Kelton, A. Robinson, A. Koeck, and K. E. Leslie. 2013. Analysis of health and survival in a population of Ontario Holstein heifer calves. J. Dairy Sci. 96:1880-1885. http://dx.doi.org/10.3168/jds.2012-5735.

Mee, J. F., D. P. Berry, and A. R. Cromie. 2008. Prevalence of, and risk factors associated with, perinatal calf mortality in pasturebased Holstein-Friesian cows. Animal 2:613-620. http://dx.doi. org/10.1017/S1751731108001699.

Norman, H. D., J. R. Wright, M. T. Kuhn, S. M. Hubbard, J. B. Cole, and P. M. VanRaden. 2009. Genetic and environmental factors that affect gestation length in dairy cattle. J. Dairy Sci. 92:2259 2269. http://dx.doi.org/10.3168/jds.2007-0982.

Pezeshki, A., J. Mehrzad, G. R. Ghorbani, H. R. Rahmani, R. J. Collier, and C. Burvenich. 2007. Effects of short dry periods on performance and metabolic status in Holstein dairy cows. J. Dairy Sci. 90:5531-5541. http://dx.doi.org/10.3168/jds.2007-0359.

Raboisson, D., F. Delor, E. Cahuzac, C. Gendre, P. Sans, and G. Allaire. 2013. Perinatal, neonatal, and rearing period mortality of dairy calves and replacement heifers in France. J. Dairy Sci. 96:2913-2924. http://dx.doi.org/10.3168/jds.2012-6010.
Reynolds, L. P., C. L. Ferrell, J. A. Nienaber, and S. P. Ford. 1985. Effects of chronic environmental heat-stress on blood-flow and nutrient-uptake of the gravid bovine uterus and fetus. J. Agric. Sci. 104:289-297.

Rutherford, K. M. D., R. D. Donald, G. Arnott, J. A. Rooke, L. Dixon, J. J. M. Mehers, J. Turnbull, and A. B. Lawrence. 2012 Farm animal welfare: Assessing risks attributable to the prenatal environment. Anim. Welf. 21:419-429. http://dx.doi. org/10.7120/09627286.21.3.419.

Şengül, Ö., A. A. Sivashığlu, M. K. Kokanalı, I. Üstüner, and A. F. Avşar. 2013. The outcomes of the pregnancies of lactating women. Turk. J. Med. Sci. 43:251-254. http://dx.doi.org/10.3906/sag1207-33.

Sharma, R. K., H. T. Blair, C. M. C. Jenkinson, P. R. Kenyon, J. F. Cockrem, and T. J. Parkinson. 2012. Uterine environment as a regulator of birth weight and body dimensions of newborn lambs. J. Anim. Sci. 90:1338-1348. http://dx.doi.org/10.2527/jas.20103800 .

Simerl, N. A., C. J. Wilcox, W. W. Thatcher, and F. G. Martin. 1991. Prepartum and peripartum reproductive performance of dairy heifers freshening at young ages. J. Dairy Sci. 74:1724-1729. http://dx.doi.org/10.3168/jds.S0022-0302(91)78335-5.

Stein, A. D., P. A. Zybert, M. van de Bor, and L. H. Lumey. 2004. Intrauterine famine exposure and body proportions at birth: The Dutch Hunger Winter. Int. J. Epidemiol. 33:831-836. http:// dx.doi.org/10.1093/ije/dyh083.

Swali, A., Z. Cheng, N. Bourne, and D. C. Wathes. 2008. Metabolic traits affecting growth rates of pre-pubertal calves and their relationship with subsequent survival. Domest. Anim. Endocrinol. 35:300-313. http://dx.doi.org/10.1016/j.domaniend.2008.06.005.

Swali, A., and D. C. Wathes. 2006. Influence of the dam and sire on size at birth and subsequent growth, milk production and fertility in dairy heifers. Theriogenology 66:1173-1184. http://dx.doi. org/10.1016/j.theriogenology.2006.03.028.

Symonds, M. E., S. P. Sebert, and H. Budge. 2010. Nutritional regulation of fetal growth and implications for productive life in ruminants. Animal 4:1075-1083. http://dx.doi.org/10.1017/ S1751731110000479.

Tao, S., A. P. Monteiro, I. M. Thompson, M. J. Hayen, and G. E. Dahl. 2012. Effect of late-gestation maternal heat stress on growth and immune function of dairy calves. J. Dairy Sci. 95:7128-7136. http://dx.doi.org/10.3168/jds.2012-5697.

Taylor, V. J., Z. Cheng, P. G. Pushpakumara, D. E. Beever, and D. C. Wathes. 2004. Relationships between the plasma concentrations of insulin-like growth factor-I in dairy cows and their fertility and milk yield. Vet. Rec. 155:583-588.

Umphrey, J. E., B. R. Moss, C. J. Wilcox, and H. H. Van Horn. 2001. Interrelationships in lactating Holsteins of rectal and skin temperatures, milk yield and composition, dry matter intake, body weight, and feed efficiency in summer in Alabama. J. Dairy Sci. 84:26802685. http://dx.doi.org/10.3168/jds.S0022-0302(01)74722-4.

Van Soom, A., L. Vandaele, K. Goossens, S. Heras, E. Wydooghe, M. B. Rahman, M. M. Kamal, M. Van Eetvelde, G. Opsomer, and L. Peelman. 2013. Epigenetics and the periconception environment in ruminants. Proc. Belgian Royal Acad. Med. 2:1-23.

Vuguin, P. M. 2007. Animal models for small for gestational age and fetal programing of adult disease. Horm. Res. 68:113-123. http:// dx.doi.org/10.1159/000100545.

Wathes, D. C., J. S. Brickell, N. E. Bourne, A. Swali, and Z. Cheng. 2008. Factors influencing heifer survival and fertility on commercial dairy farms. Animal 2:1135-1143. http://dx.doi.org/10.1017/ S1751731108002322.

Weber, W. J., C. R. Wallace, L. B. Hansen, H. Chester-Jones, and B. A. Crooker. 2007. Effects of genetic selection for milk yield on somatotropin, insulin-like growth factor-I, and placental lactogen in Holstein cows. J. Dairy Sci. 90:3314-3325. http://dx.doi. org $/ 10.3168 /$ jds.2006-899.

Wilkin, T. J., and M. J. Murphy. 2006. The gender insulin hypothesis: Why girls are born lighter than boys, and the implications for insulin resistance. Int. J. Obes. (Lond.) 30:1056-1061. http://dx.doi. org/10.1038/sj.ijo.0803317. 
Wu, G., F. W. Bazer, J. M. Wallace, and T. E. Spencer. 2006. Intrauterine growth retardation: Implications for the animal sciences. J. Anim. Sci. 84:2316-2337. http://dx.doi.org/10.2527/jas.2006156.

Yamazaki, T., H. Takeda, A. Nishiura, Y. Sasai, N. Sugawara, and K. Togashi. 2011. Phenotypic relationship between lactation persistency and change in body condition score in first-lactation Hol- stein cows. Asian-australas. J. Anim. Sci. 24:610-615. http:// dx.doi.org/10.5713/ajas.2011.10271

Zhang, W.-C., T. Nakao, K. Kida, M. Moriyoshi, and K. Nakada. 2002. Effect of nutrition during pregnancy on calf birth weights and viability and fetal membrane expulsion in dairy cattle. J. Reprod. Dev. 48:415-422. 